\title{
Virginia Commonwealth University
}

VCU Scholars Compass

2014

\section{Chronic behavioral and cognitive deficits in a rat survival model of paraoxon toxicity}

Laxmikant Sudhir Deshpande

VirginiaCommonwealth University, laxmikant.deshpande@vcuhealth.org

Kristin Phillips

Virginia Commonwealth University, fentonkl@vcu.edu

Beverly Huang

Virginia Commonwealth University, huangba@vcu.edu

Robert J. DeLorenzo

Virginia Commonwealth University, rdeloren@vcu.edu

Follow this and additional works at: http://scholarscompass.vcu.edu/neurology_pubs

Part of the Neurology Commons

(C) 2014 Elsevier Inc. All rights reserved. NOTICE: this is the author's version of a work that was accepted for publication in NeuroToxicology. Changes resulting from the publishing process, such as peer review, editing, corrections, structural formatting, and other quality control mechanisms may not be reflected in this document. Changes may have been made to this work since it was submitted for publication. A definitive version was subsequently published in NeuroToxicology Volume 44, September 2014, Pages 352-357, doi:10.1016/j.neuro.2014.08.008.

\section{Downloaded from}

http://scholarscompass.vcu.edu/neurology_pubs/10

This Article is brought to you for free and open access by the Dept. of Neurology at VCU Scholars Compass. It has been accepted for inclusion in Neurology Publications by an authorized administrator of VCU Scholars Compass. For more information, please contact libcompass@vcu.edu. 


\section{Chronic behavioral and cognitive deficits in a rat survival model of paraoxon toxicity}

Laxmikant S. Deshpande* Kristin Phillips*, Beverly Huang ${ }^{*}$, and Robert J. DeLorenzo ${ }^{1 *} \dagger$

Departments of Neurology*, Pharmacology and Toxicology ${ }^{\dagger}$, Neuroscience $^{\#}$, and Molecular Biophysics and Biochemistry ${ }^{\ddagger}$. Virginia Commonwealth University, Richmond, Virginia 23298, USA

To whom correspondence should be addressed:

${ }^{1}$ Robert J. DeLorenzo, M.D., Ph.D., M.P.H.

Virginia Commonwealth University

School of Medicine

PO Box 980599

Richmond, VA 23298

Phone: 804-828-3392

Fax: 804-828-6432

E-mail: rdeloren@hsc.vcu.edu 


\begin{abstract}
Organophosphate (OP) compounds, including paraoxon (POX), are similar to nerve agents such as sarin. There is a growing concern that OP agents could be weaponized to cause mass civilian causalities. We have developed a rodent survival model of POX toxicity that is being used to evaluate chronic morbidity and to screen for medical countermeasures against severe OP exposure. It is well known that the survivors of nerve gas and chronic OP exposure exhibit neurobehavioral deficits such as mood changes, depression, and memory impairments. In this study we investigated whether animals surviving severe POX exposure exhibited long-term neurological impairments. POX exposure produced overt signs of cholinergic toxicity. Rats were rescued using an optimized atropine, 2-PAM and diazepam therapy. Surviving rats were studied using established behavioral assays for identifying symptoms of depression and memory impairment 3-months after POX exposure. In the forced swim test, POX rats exhibited increased immobility time indicative of a despair-like state. In the sucrose preference test, POX rats consumed significantly less sucrose water indicating anhedonia-like condition. POX rats also displayed increased anxiety as characterized by significantly lower performance in the open arm of the elevated plus maze. Further, when tested with a novel object recognition paradigm, POX rats exhibited a negative discrimination ratio indicative of impaired recognition memory. The results indicate that this model of survival from severe POX exposure can be employed to study some of the molecular bases for OP-induced chronic behavioral and cognitive comorbidities and develop therapies for their treatment.
\end{abstract}

Keywords: paraoxon, chronic depression, anxiety, memory impairments, Sprague-Dawley rats 


\section{Introduction}

The use of nerve gas in the recent Syrian civil war, deaths and severe illness in Indian children following consumption of pesticide contaminated lunches, weaponization of paraoxon and parathion during the Rhodesian war, and the deadly 2005 chlorine release following the train accident in Graniteville, SC, USA are some of the recent examples of the civilian population being exposed to highly toxic pesticides, chemicals and nerve agents (Croddy et al. , 2004, Gould and Folb, 2003, Hood, 2001, Nishiwaki et al. , 2001, Than, 2013). Organophosphate pesticides (OP) such as parathion, paraoxon (POX) and diisopropyl fluorophosphate (DFP) are highly dangerous chemicals and are used in civilian laboratories as nerve agent surrogates. Exposure to OPs, occupational, accidental or intentional, is a major global health problem particularly in developing countries (Konradsen, 2007). OP agents are potent inhibitors of the enzyme acetylcholinesterase (AChE). Inhibition of AChE leads to build up of the neurotransmitter acetylcholine (ACh) at the nerve synapses, acutely producing cholinergic symptoms such as salivation, lacrimation, blurred vision and tremors that may evolve into unremitting seizures (status epilepticus, SE) if synaptic ACh levels are very high (Bajgar, 2004). If left untreated, individuals exposed to high doses of OP can suffer rapid death (McDonough et al. , 1995).

Unfortunately, survivors of OP exposure and SE suffer from a number of neurological problems (de Araujo Furtado et al. , 2012, Garcia et al. , 2003). Human (Brown and Brix, 1998, Rauh et al. , 2012, Ruckart et al. , 2004) and animal (Ivens et al. , 1998, Johnson et al. , 2009, Levin et al. , 2010, Terry et al. , 2012) studies have linked OP exposure to behavioral changes and altered cognition. An animal model that would mimic both acute and chronic effects of 
severe OP exposure could help in deciphering mechanisms underlying the development of chronic morbidities in OP exposed animals.

We have recently reported the development of a rat survival model of severe OP intoxication using POX and DFP (Deshpande et al. , 2010, Deshpande et al. , 2014). The mortality, behavioral manifestations, and electroencephalogram profile for DFP and POXinduced cholinergic crisis were identical to those reported for human OP and nerve agent exposures. By optimizing the standard three-drug regimen of atropine, pralidoxime chloride (2PAM), and diazepam we were able to achieve a significantly higher survival rates. We also observed multi-focal neuronal injury and protracted hippocampal $\mathrm{Ca}^{2+}$ elevations following severe DFP and POX exposures (Deshpande et al. , 2010, Deshpande et al. , 2014). Given the

critical role of $\mathrm{Ca}^{2+}$ signaling in neuronal plasticity, these severe OP induced alterations in $\mathrm{Ca}^{2+}$ dynamics could underlie some of the long-term plasticity changes associated with OP and nerve agent toxicity (Filbert et al. , 2005). In this study, we investigated whether rats treated using the standard atropine, 2-PAM and diazepam therapy following exposure to severe POX exhibited long-term neurological deficits.

\section{Materials and methods}

\section{Animals}

All animal use procedures were in strict accordance with the National Institute of Health Guide for the Care and Use of Laboratory Animals and approved by Virginia Commonwealth University's Institutional Animal Care and Use Committee. Male Sprague-Dawley rats (Harlan, Indianapolis, IN) weighing 260-300 g and 9-10 weeks age were used in this study. Animals were housed two per cage at $20-22^{\circ} \mathrm{C}$ with a 12 Light: 12 Dark hour cycle (lights on 0600-01800 h) and free access to food and water. 


\section{Chemicals}

All the chemicals were obtained from Sigma Aldrich Company (St. Louis, MO) unless otherwise noted. POX was dissolved in ice-cold phosphate buffered saline just before the experiment and injected sub-cutaneously (s.c.). Atropine and pralidoxime chloride (2-PAM) were dissolved in saline $(0.9 \% \mathrm{NaCl})$. Diazepam in injectable form was obtained from VCU Health System pharmacy. POX was always prepared fresh daily and kept on ice until the time of injections. All other drugs were also prepared fresh on the day of experiment.

\section{POX exposure}

Rats were injected with POX (4 mg/kg, s.c.) followed by atropine sulfate ( $2 \mathrm{mg} / \mathrm{kg}$, i.p.) and 2-PAM (25 mg/kg, i.m.) one minute later. Within minutes, rats manifested gross behavioral changes such as increased grooming, chewing and the Straub tail response. These led to classical hyper-cholinergic symptoms, including respiratory distress, increased salivation, defecation, urination and tonic-clonic seizures. To mimic the time required for emergency personnel to reach the site of OP release and start treating the exposed individuals, rats were rescued approximately 1-h following POX exposure using an optimized FDA approved treatment regimen with diazepam (5 mg/kg, i.p) and 2-PAM (25 mg/kg, i.m.). Given the short half-life of 2-PAM and to prevent seizures from re-occurring, these injections were repeated at 3 and 5-h (Deshpande et al., 2014). At the end of all the injections, surviving animals were supplemented with $3 \mathrm{~mL}$ saline solution (i.p.) and sucrose milk (p.o.). Control rats received POX vehicle and all the drug injections at respective time points. Animal health was reassessed every day for the next three days and wet-chow and saline was administered if weight gain did not occur. By the fourth-day all the survivors had recovered from POX induced cholinergic crisis and were mobile. Surviving rats were housed individually in a temperature and light controlled vivarium. All the rats were 
weighed and visually monitored once a week until their use in behavioral experiments. No significant differences were observed in the weight gain dynamics between the controls and POX-treated rats (Table 1). Chronic mortality (72-h and beyond) in this model of severe POX intoxication was about 18-20\% (Deshpande et al. , 2014). Mazarati et al., has established criteria for controlling unusual behavior or seizure activity in conducting behavioral assays following SE. Using these methods at 12 -weeks following severe POX exposure rats were subjected to video monitoring for a period of 6-h preceding and during the behavioral tests (Mazarati et al. , 2009). We did not observe any unusual behavior or clinical seizures in the rats during the tests.

\section{Assessment of depression and memory}

Each behavior sub-type was analyzed using specific tests that are widely used by investigators studying these conditions (Brooks-Kayal et al. , 2013). All the behavioral assays were carried out between 12-14 weeks following POX exposure. Testing was carried out in a quiet, dimly lit room between 0800 to $1400 \mathrm{hrs}$. Depression is a complex psychological phenomenon and as such is difficult to analyze using a single test (Overstreet, 2012). For identifying depressive symptoms the Forced Swim Test (FST) that models despair along with the Sucrose Preference Test (SPT) that signifies anhedonia were used. Anxiety was tested using Elevated Plus Maze (EPM) paradigm. Together, the helplessness, despair, lack of feeling pleasure and anxiety constitute the symptoms of depression-like state in rats. Like depression, assessment of memory is a complex behavioral task (Bevins and Besheer, 2006). Memory was tested using Novel Object Recognition (NOR) test, which is similar to the human delayed nonmatch to sample task and assess pre-frontal function. Rats were first subjected to SPT followed by NOR, then EPM and finally FST. No two tests were carried out on the same day. These tests are described below. 


\section{Forced Swim Test (FST)}

Porsolt's modified FST was used to assess behavioral despair (Overstreet, 2012). Briefly, animals were forced to swim by being placed in a glass cylindrical chamber $(46 \mathrm{~cm} \mathrm{H} \mathrm{x} 30 \mathrm{~cm} \mathrm{D})$ filled with water $\left(30 \mathrm{~cm}\right.$ height, $\left.25^{\circ} \mathrm{C}\right)$. Two swimming sessions were carried out with an initial 15 min 'pre-test' followed by a 5 min 'test' after $24 \mathrm{~h}$. Active (swimming, climbing, diving) and passive (immobility) behavior was evaluated by 2 reviewers blinded to the treatment conditions. Immobility (primary outcome) was defined as the period during which the animal floats in the water making only those movements necessary to keep its head above water. The tank was emptied and thoroughly cleaned for every rat to be tested in a session.

\section{Sucrose Preference Test (SPT)}

This test measures hedonia (pleasure-seeking) or lack of it (anhedonia) by monitoring a rat's preference to sucrose water (Overstreet, 2012). Briefly, rats were habituated to having two bottles in the cage lid for three days. The bottles were fitted with ball-bearing sipper tubes that prevented fluids from leaking. Following this acclimation, rats had the free choice of either drinking the $1 \%$ sucrose solution or plain water for a period of 2 days. Water and sucrose solution intake was measured daily, and the positions of two bottles were switched daily to reduce any confounding effects produced by a side bias. Sucrose preference was calculated as a percentage of the volume of sucrose intake over the total volume of fluid intake and averaged over the 2 days of testing. Reviewers were blinded to treatment conditions.

\section{Elevated Plus Maze (EPM)}

This test assesses anxiety by taking into account innate behavior of rats to prefer dark enclosed spaces over bright open spaces (Walf and Frye, 2007). The maze (Med Associates Inc., St. Albans, VT) was made of black polyvinyl chloride and consists of four arms, $50 \mathrm{~cm}$ long x 10 
$\mathrm{cm}$ wide, connected by a central square, $10 \times 10 \mathrm{~cm}$ : two open without walls and two closed by 31-cm-high walls. All arms were attached to sturdy metal legs; the maze was elevated $55 \mathrm{~cm}$ above the floor level and was set in a dimly lit room. A video camera was suspended above the maze to record the rat movements for analysis. A video-tracking system (Noldus Ethovision XT 9) was used to automatically collect behavioral data. The procedure consisted of placing the rats at the junction of the open and closed arms, the center of the maze, facing the open arm opposite to where the experimenter was. The video-tracking system was started after the animal was placed in the maze so that the behavior of each animal was consistently recorded for $5 \mathrm{~min}$. At the end of the 5 min test session, the rat was removed from the plus maze and returned to its home cage. The maze was cleaned with $70 \%$ ethanol to remove any scent traces and allowed to dry completely before introducing the next animal in the arena. Time spent and entries made in the open arm were calculated.

\section{Novel Object Recognition (NOR)}

Briefly, rats were placed in black Perspex box $60 \times 90 \times 50 \mathrm{~cm}$ in a dimly illuminated and quite animal behavior testing room. Rats were habituated individually, by allowing them to explore the box for 15-min per session for 3 days. The arena was cleaned with a $70 \%$ ethanol solution and dried completely in between each subject so as to eliminate any potential odor cues left by previous subjects. On the fourth day, in the sample phase, two identical objects (A) were placed in opposite corners of the box, $20 \mathrm{~cm}$ from the wall. A rat was allowed to explore for 3min, and then it was removed from the box and returned to its home cage. In the choice phase (3h later), one familiar object was replaced by a novel object (B), and the rat was allowed to explore for 2-min. Objects were similar in size and emotionally neutral, but varied for shape, color and texture. Behavior was recorded by a digital camera mounted above the experimental 
box. Direct contacts included any contact with mouth, nose or paw and did not include contacts that were accidental (backing or bumping into the object). Also, standing, sitting or leaning on the object was not scored as object interaction. We determined a discrimination ratio, which is a difference in the exploration time divided by the total time spent exploring the two objects in the choice phase: $([\mathrm{B}-\mathrm{A}] /[\mathrm{B}+\mathrm{A}])$. A time-dependent decline in preference for novel object is likely reflective of memory decline for familiar object (Bevins and Besheer, 2006).

\section{Data analysis}

Data were analyzed and graphs plotted using the Sigmaplot 12.3 software (SPSS Inc, Chicago, IL). All the data that passed the normality test was further subjected to t-test. $\mathrm{p}<0.05$ was considered significant for all data analysis.

\section{Results}

\section{Performance on FST}

The FST was an effective test in evaluating the presence of a despair-like state in the POX intoxication survival model. POX toxicity survivor rats subjected to the modified FST exhibited increased immobility time $(88.5 \pm 8.5 \mathrm{~s})$ that was significantly higher compared to the immobility time $(39.5 \pm 7.5 \mathrm{~s})$ in age matched control rats $(\mathrm{p}<0.01, \mathrm{n}=8$, Fig. 1$)$.

\section{Performance on SPT}

POX toxicity survivor animals also displayed absence of preferential sucrose consumption on SPT. POX rats consumed $48.5 \pm 5.7 \%$ sucrose-laced water and $52.5 \pm 4.2 \%$ of non-sweetened water. In contrast, age-matched control rats overwhelmingly preferred sucrose water $(75.6 \pm 5.7 \%)$ over non-sweetened water $(24.4 \pm 4.2 \%)$. This indicates presence of anhedonia in the POX SE rats $(\mathrm{p}<0.01, \mathrm{n}=8$, Fig. 2A). No differences were found between total 
fluid consumption and fluid consumed on right vs. left amongst the two groups $(\mathrm{p}>0.5, \mathrm{n}=8$, Fig. 2B).

\section{Performance on EPM}

POX toxicity survivor rats displayed significant anxiety-like behavior compared to agematched control rats. POX rats spent significantly less time $(2.4 \pm 1.9 \%$ vs. $16.9 \pm 4.5 \%)$ and made significantly less entries $(13.5 \pm 6.7 \%$ vs. $34.4 \pm 5.5 \%)$ in the open-arm of EPM compared to age-matched control rats ( $\mathrm{p}<0.05, \mathrm{n}=8$, Figs. 3A, B). To investigate whether these differences in open-arm behavior were not due to global differences in exploratory or locomotor activity, we also measured the distance travelled and total arm entries. No significant differences were observed in these two parameters between the rats in the two groups ( $p>0.5, n=8$, Figs. 3C, D).

\section{Performance on NOR}

In the choice phase of NOR, POX intoxicated rats spent more time exploring the old object compared to the new object indicating that these rats did not remember the familiar object. In contrast, age-matched control rats spent more time exploring the novel object indicating that these rats remembered the familiar object. Thus, the POX toxicity survivor rats exhibited a negative discrimination ratio $(-0.06 \pm 0.15)$ indicative of impaired recognition memory that was significantly lower compared to age matched control rats $(0.79 \pm 0.05)(\mathrm{p}<0.01, \mathrm{n}=8$, Fig. 4A). In the sample phase (3-h earlier) no significant exploratory preference was found between the two groups and rats from both the group spent similar time exploring the two objects $(\mathrm{p}>0.5, \mathrm{n}=$ 8, Fig. 4B).

\section{Discussion}

In this study, we observed behavioral depression-like symptoms and cognitive deficits in rats surviving severe POX exposure. There is evidence from the civilian population indicating 
that both repeated exposure to OP insecticides (Rosenstock et al. , 1991, Savage et al. , 1988, Wesseling et al. , 2002) or a single acute exposure to nerve agents as seen in the survivors and first responders of the Tokyo subway sarin gas attack (Hood, 2001, Nishiwaki et al., 2001) can lead to chronic neurological morbidities including cognitive deficits, mood disorders and depression. Approximately 35\% of soldiers deployed in the 1991 Persian Gulf War suffered from chronic multi-symptom illnesses characterized by depression and cognitive deficits (Committee on Gulf War and Health, 2010). A leading cause for the Gulf War syndrome in these veterans is thought to be OP/ nerve agent exposure during deployment (Brimfield, 2012). SE is also known to produce cognitive deficits by affecting the hippocampus and changing the functional neuronal networks in the brain (Tyler et al. , 2012). Our recent study (Deshpande et al., 2014) along with the data presented here demonstrate that the POX model mimics both the acute hyper-cholinergic response and also exhibits chronic behavioral impairments and cognitive deficits in POX intoxication survivor rats.

Numerous animal studies have documented the detrimental effects of pesticides exposure on neurobehavioral parameters (Brown and Brix, 1998, Burns et al. , 2013). In these studies both the cause and effect of high-dose OP exposure was studied acutely. For example, Malathion administered 30-min prior to behavioral tests produced deficits on FST and EPM paradigms (Assini et al. , 2005). In another study, behavioral effects of DFP intoxication were studied at 7 and 30-days post exposure. In the absence of any mortality, DFP rats exhibited deficits in FST but not on EPM (Wright et al. , 2009). In other studies, environmental OP exposures that are not associated with overt signs of toxicity were mimicked by administering OP's such as chlorpyrifos, Malathion, Parathion or DFP at low doses chronically either in-utero or in adolescent or adult rats and behavioral testing was conducted 7-30 days post exposure (Chen et 
al. , 2011, Ivens et al. , 1998, Lima et al. , 2009, Terry et al. , 2012, Timofeeva et al. , 2008, Venerosi et al. , 2010, Yan et al. , 2012). Significant alterations in behavior and memory were noted in these animals using the behavioral tests also used in this study. To our knowledge, our study is the first report that demonstrates chronic neuropsychiatric deficits in rats surviving a severe OP exposure that are treated with standard 3-drug atropine + 2-PAM + diazepam therapy.

The hippocampus plays a major role in the limbic system, is essential in memory functioning (Battaglia et al. , 2011) and also plays an important role in the pathophysiology of depression (Campbell and Macqueen, 2004). $\mathrm{Ca}^{2+}$ is a major second messenger and is vital to cellular signaling, developing neuronal plasticity which controls behavior, and memory (Baker et al. , 2013, Bengtson and Bading, 2012). Thus, the levels of $\mathrm{Ca}^{2+}$ are tightly regulated by an intricate system of ion-channels, buffers, pumps and ER. Brief elevations in $\mathrm{Ca}^{2+}$ levels are critical to cellular communication and long-term potentiation (learning and memory consolidation). However, our research and that of other investigators have demonstrated that sustained $\mathrm{Ca}^{2+}$ elevations particularly in the hippocampal region are detrimental to the cell and are implicated in many neurological disorders including Alzheimer's disease (Chadwick et al. , 2013), Parkinson's disease (Surmeier and Schumacker, 2013), traumatic brain injury (Sun et al. , 2008), aging (Raza et al. , 2007), epilepsy (Nagarkatti et al. , 2009) and stroke (Deshpande et al. , 2007). These neurological conditions are typically associated with cognitive deficits and other bio-behavioral disorders. In addition to the alterations in hippocampal $\mathrm{Ca}^{2+}$ dynamics, these neurological disorders also exhibit neuronal damage in discreet brain regions. Brain lesion and neuropathology studies have demonstrated an association between neuronal injury and behavioral symptoms. For example, lesions to amygdalar interneurons in rats produce increased anxiety-like behaviors (Truitt et al., 2009). Lesions to specific hippocampal neurons produce 
cognitive deficits and anxiety (Barkus et al., 2010). Traumatic brain injury that damages neurons in the hippocampus, cortex and thalamus is often associated with cognitive deficits and depressive symptoms (Raghupathi, 2004). Ischemic insult such as those observed during stroke damages the hippocampus leading to an increased risk of post-stroke depression and memory impairments (Loubinoux et al., 2012). We recently reported neuronal damage in multiple brain regions including the hippocampus, amygdala, and cortex in a rat survival model of POX toxicity (Deshpande et al., 2014). This wide-spread neuronal damage could possibly underlie the expression of behavioral deficits observed in severe POX toxicity survivors.

We earlier reported that severe OP exposure is associated with N-methyl-D-aspartate receptor dependent significant elevation in hippocampal neuronal calcium levels that lasted for weeks following the termination of OP induced SE (Deshpande et al. , 2010, Deshpande et al. , 2014). These sustained elevations in hippocampal neuronal calcium levels had its origins in $\mathrm{Ca}^{2+}$ release from intracellular stores in the endoplasmic reticulum, since blockade of intracellular $\mathrm{Ca}^{2+}$ induced $\mathrm{Ca}^{2+}$ release using inhibitors of ryanodine receptor and inositol trisphosphate receptor such as dantrolene, levetiracetam and carisbamate prevented the development of sustained $\mathrm{Ca}^{2+}$ plateau following OP toxicity (Deshpande et al., 2014). It will be important to study whether these intracellular $\mathrm{Ca}^{2+}$ lowering agents when administered after severe OP exposure could also prevent or modify the symptoms of chronic morbidities. This model is ideal to study molecular mechanisms underlying the development of long term neurological deficits and screen newer agents to limit mortality and morbidity following severe OP exposures. 


\section{Acknowledgements}

This work was supported by the CounterACT Program, National Institutes of Health Office of the Director (NIH OD), and the National Institute of Neurological Disorders and Stroke [Grant Number U01NS058213 and R21NS072061] to RJD. Its contents are solely the responsibility of the authors and do not necessarily represent the official views of the federal government. 


\section{References}

Assini FL, Zanette KD, Brocardo PS, Pandolfo P, Rodrigues AL, Takahashi RN. Behavioral effects and $\mathrm{ChE}$ measures after acute and repeated administration of malathion in rats. Environ Toxicol Pharmacol. 2005;20:443-9.

Bajgar J. Organophosphates/nerve agent poisoning: mechanism of action, diagnosis, prophylaxis, and treatment. Adv Clin Chem. 2004;38:151-216.

Baker KD, Edwards TM, Rickard NS. The role of intracellular calcium stores in synaptic plasticity and memory consolidation. Neurosci Biobehav Rev. 2013;37:1211-39.

Barkus C, McHugh SB, Sprengel R, Seeburg PH, Rawlins JN, Bannerman DM. Hippocampal NMDA receptors and anxiety: at the interface between cognition and emotion. Eur J Pharmacol. 2010;626(1):49-56.

Battaglia FP, Benchenane K, Sirota A, Pennartz CM, Wiener SI. The hippocampus: hub of brain network communication for memory. Trends Cogn Sci. 2011;15:310-8.

Bengtson CP, Bading H. Nuclear calcium signaling. Adv Exp Med Biol. 2012;970:377-405.

Bevins RA, Besheer J. Object recognition in rats and mice: a one-trial non-matching-to-sample learning task to study 'recognition memory'. Nat Protocols. 2006;1:1306-11.

Brimfield AA. Chemicals of military deployments: revisiting Gulf War Syndrome in light of new information. Prog Mol Biol Transl Sci. 2012;112:209-30.

Brooks-Kayal AR, Bath KG, Berg AT, Galanopoulou AS, Holmes GL, Jensen FE, Kanner AM, O'Brien TJ, Whittemore VH, Winawer MR, Patel M, Scharfman HE. Issues related to symptomatic and disease-modifying treatments affecting cognitive and neuropsychiatric comorbidities of epilepsy. Epilepsia. 2013;54 Suppl 4:44-60.

Brown MA, Brix KA. Review of health consequences from high-, intermediate- and low-level exposure to organophosphorus nerve agents. J Appl Toxicol. 1998;18:393-408.

Burns CJ, McIntosh LJ, Mink PJ, Jurek AM, Li AA. Pesticide exposure and neurodevelopmental outcomes: review of the epidemiologic and animal studies. J Toxicol Environ Health B Crit Rev. 2013;16:127-283.

Campbell S, Macqueen G. The role of the hippocampus in the pathophysiology of major depression. J Psychiatry Neurosci. 2004;29:417-26.

Chadwick W, Mitchell N, Martin B, Maudsley S. Therapeutic targeting of the endoplasmic reticulum in Alzheimer's disease. Curr Alzheimer Res. 2013;9:110-9.

Chen WQ, Yuan L, Xue R, Li YF, Su RB, Zhang YZ, et al. Repeated exposure to chlorpyrifos alters the performance of adolescent male rats in animal models of depression and anxiety. Neurotoxicology. 2011;32:355-61.

Croddy E, Wirtz J, Larsen J. Weapons of Mass Destruction: An Encyclopedia of Worldwide Policy, Technology, and History. Santa Barbara, CA: ABC-CLIO; 2004.

de Araujo Furtado M, Rossetti F, Chanda S, Yourick D. Exposure to nerve agents: from status epilepticus to neuroinflammation, brain damage, neurogenesis and epilepsy. Neurotoxicology. 2012;33:1476-90. 
DeLorenzo RJ, Sun DA, Deshpande LS. Cellular mechanisms underlying acquired epilepsy: the calcium hypothesis of the induction and maintainance of epilepsy. Pharmacol Ther. 2005;105:229-66.

Deshpande LS, Carter DS, Blair RE, DeLorenzo RJ. Development of a prolonged calcium plateau in hippocampal neurons in rats surviving status epilepticus induced by the organophosphate diisopropylfluorophosphate. Toxicol Sci. 2010;116:623-31.

Deshpande LS, Carter DS, Phillips KF, Blair RE, DeLorenzo RJ. Development of status epilepticus, sustained calcium elevations and neuronal injury in a rat survival model of lethal paraoxon intoxication. Neurotoxicology. 2014;44C:17-26.

Deshpande LS, Limbrick DD, Jr., Sombati S, DeLorenzo RJ. Activation of a novel injuryinduced calcium-permeable channel that plays a key role in causing extended neuronal depolarization and initiating neuronal death in excitotoxic neuronal injury. J Pharmacol Exp Ther. 2007;322:443-52.

Filbert M, Levine E, Ballough G. Neuroprotection for nerve agent-induced brain damage by blocking delayed calcium overload: a review. J Med CBR Def. 2005;3.

Garcia SJ, Abu-Qare AW, Meeker-O'Connell WA, Borton AJ, Abou-Donia MB. Methyl parathion: a review of health effects. J Toxicol Environ Health B Crit Rev. 2003;6:185-210.

Gould C, Folb PI. Project Coast: Apartheid's Chemical and Biological Warfare Programme. United Nations; 2003.

Hesdorffer DC, Logroscino G, Cascino G, Annegers JF, Hauser WA. Risk of unprovoked seizure after acute symptomatic seizure: effect of status epilepticus. Ann Neurol. 1998;44:908-12.

Hood E. The Tokyo attacks in retrospect: sarin leads to memory loss. Environ Health Perspect. 2001;109:A542.

Committee on Gulf War and Health. GULF WAR and HEALTH: Treatment for Chronic Multisymptom Illness. 2010.

Ivens IA, Schmuck G, Machemer L. Learning and memory of rats after long-term administration of low doses of parathion. Toxicol Sci. 1998;46:101-11.

Johnson FO, Chambers JE, Nail CA, Givaruangsawat S, Carr RL. Developmental chlorpyrifos and methyl parathion exposure alters radial-arm maze performance in juvenile and adult rats. Toxicol Sci. 2009; 109:132-42.

Konradsen F. Acute pesticide poisoning-a global public health problem. Danish medical bulletin. 2007;54:58-9.

Levin ED, Timofeeva OA, Yang L, Petro A, Ryde IT, Wrench N, Seidler FJ, Slotkin TA. Early postnatal parathion exposure in rats causes sex-selective cognitive impairment and neurotransmitter defects which emerge in aging. Behav Brain Res. 2010;208:319-27.

Lima CS, Ribeiro-Carvalho A, Filgueiras CC, Manhaes AC, Meyer A, Abreu-Villaca Y. Exposure to methamidophos at adulthood elicits depressive-like behavior in mice.

Neurotoxicology. 2009;30:471-8. 
Loubinoux I, Kronenberg G, Endres M, Schumann-Bard P, Freret T, Filipkowski RK, Kaczmarek L, Popa-Wagner A. Post-stroke depression: mechanisms, translation and therapy. J Cell Mol Med. 2012;16(9):1961-9.

Mazarati AM, Shin D, Kwon YS, Bragin A, Pineda E, Tio D, Taylor AN, Sankar R. Elevated plasma corticosterone level and depressive behavior in experimental temporal lobe epilepsy. Neurobiol Dis. 2009;34:457-61.

McDonough JH, Jr., Dochterman LW, Smith CD, Shih TM. Protection against nerve agentinduced neuropathology, but not cardiac pathology, is associated with the anticonvulsant action of drug treatment. Neurotoxicology. 1995;16:123-32.

Nagarkatti N, Deshpande LS, DeLorenzo RJ. The Role of calcium in mediating neuronal plasticity in epileptogenesis. In: Schwartzkroin PA, editor. Encyclopedia of Basic Epilepsy Research. Oxford: Academic Press; 2009. p. 1181-9.

Nishiwaki Y, Maekawa K, Ogawa Y, Asukai N, Minami M, Omae K, Sarin Health Effects Study Group. Effects of sarin on the nervous system in rescue team staff members and police officers 3 years after the Tokyo subway sarin attack. Environ Health Perspect. 2001;109:1169-73.

Overstreet DH. Modeling depression in animal models. Methods Mol Biol. 2012;829:125-44.

Raghupathi R. Cell death mechanisms following traumatic brain injury. Brain Pathol. 2004;14(2):215-22.

Rauh VA, Perera FP, Horton MK, Whyatt RM, Bansal R, Hao X, Liu J, Barr DB, Slotkin TA, Peterson BS. Brain anomalies in children exposed prenatally to a common organophosphate pesticide. Proc Natl Acad Sci U S A. 2012;109:7871-6.

Raza M, Deshpande LS, Blair RE, Carter DS, Sombati S, DeLorenzo RJ. Aging is associated with elevated intracellular calcium levels and altered calcium homeostatic mechanisms in hippocampal neurons. Neurosci Lett. 2007;418:77-81.

Rosenstock L, Keifer M, Daniell WE, McConnell R, Claypoole K. Chronic central nervous system effects of acute organophosphate pesticide intoxication. The Lancet. 1991;338:223-7.

Ruckart PZ, Kakolewski K, Bove FJ, Kaye WE. Long-term neurobehavioral health effects of methyl parathion exposure in children in Mississippi and Ohio. Environ Health Perspect. 2004;112:46-51.

Savage EP, Keefe TJ, Mounce LM, Heaton RK, Lewis JA, Burcar PJ. Chronic neurological sequelae of acute organophosphate pesticide poisoning. Arch Environ Health. 1988;43:38-45.

Sun DA, Deshpande LS, Sombati S, Baranova A, Wilson MS, Hamm RJ, DeLorenzo RJ. Traumatic brain injury causes a long-lasting calcium-plateau of elevated intracellular calcium levels and altered calcium homeostatic mechanisms in hippocampal neurons surviving the brain injury. Eur J Neurosci. 2008;27:1659-72.

Surmeier DJ, Schumacker PT. Calcium, bioenergetics, and neuronal vulnerability in Parkinson's disease. J Biol Chem. 2013;288:10736-41.

Terry AV, Jr., Beck WD, Warner S, Vandenhuerk L, Callahan PM. Chronic impairments in spatial learning and memory in rats previously exposed to chlorpyrfos or diisopropylfluorophosphate. Neurotoxicol Teratol. 2012;34:1-8. 
Than K. Organophosphates: A Common But Deadly Pesticide.

http://news.nationalgeographic.com/news/2013/07/130718-organophosphates-pesticides-indianfood-poisoning/

Timofeeva OA, Sanders D, Seemann K, Yang L, Hermanson D, Regenbogen S, et al. Persistent behavioral alterations in rats neonatally exposed to low doses of the organophosphate pesticide, parathion. Brain Res Bull. 2008;77:404-11.

Truitt WA, Johnson PL, Dietrich AD, Fitz SD, Shekhar A. Anxiety-like behavior is modulated by a discrete subpopulation of interneurons in the basolateral amygdala. Neuroscience. 2009;160(2):284-94.

Tyler AL, Mahoney JM, Richard GR, Holmes GL, Lenck-Santini PP, Scott RC. Functional network changes in hippocampal CA1 after status epilepticus predict spatial memory deficits in rats. J Neurosci. 2012;32:11365-76.

Venerosi A, Ricceri L, Rungi A, Sanghez V, Calamandrei G. Gestational exposure to the organophosphate chlorpyrifos alters social-emotional behaviour and impairs responsiveness to the serotonin transporter inhibitor fluvoxamine in mice. Psychopharmacology (Berl). 2010;208:99-107

Walf AA, Frye CA. The use of the elevated plus maze as an assay of anxiety-related behavior in rodents. Nat Protocols. 2007;2:322-8.

Wesseling C, Keifer M, Ahlbom A, McConnell R, Moon JD, Rosenstock L, Hogstedt C. Longterm neurobehavioral effects of mild poisonings with organophosphate and n-methyl carbamate pesticides among banana workers. Int J Occup Environ Health. 2002;8:27-34.

Wright LK, Liu J, Nallapaneni A, Pope CN. Behavioral sequelae following acute diisopropylfluorophosphate intoxication in rats: Comparative effects of atropine and cannabinomimetics. Neurotoxicol Teratol. 2009;32:329-35.

Yan C, Jiao L, Zhao J, Yang H, Peng S. Repeated exposures to chlorpyrifos lead to spatial memory retrieval impairment and motor activity alteration. Neurotoxicol Teratol. 2012;34:442-9. 
Table 1 Body weight changes during the study

\begin{tabular}{|l|c|c|}
\hline Experimental Group & Weight before SE (g) & Weight 12-weeks post SE (g) \\
\hline Control & $303.4 \pm 6.4$ & $521.2 \pm 14.6$ \\
\hline POX & $306.4 \pm 5.6$ & $528.2 \pm 16.2$ \\
\hline
\end{tabular}

Data presented as mean $\pm \mathrm{SD}(\mathrm{n}=8$ rats, $\mathrm{p}=0.4$, $t$-test $)$ 


\section{Figure Legends}

Figure 1. Increased immobility time in POX intoxicated rats during FST. The immobility time in POX rats was significantly higher compared to age matched control rats. Data expressed as mean \pm SEM, $* p<0.05$, t-test, $\mathrm{n}=8$ rats.

Figure 2. Loss of sucrose consumption preference in POX intoxicated rats on SPT. Control rats overwhelmingly consumed sucrose water over regular water, whereas POX rats did not exhibit any such preference indicating anhedonia-like condition. Data expressed as mean $\pm \mathrm{SEM}$, ${ }^{*} p<0.05, \mathrm{t}$-test, $\mathrm{n}=8$ rats.

Figure 3. Increased anxiety in POX intoxicated rats on EPM test. POX rats displayed significantly lower open arm time (A) and open arm entries (B) compared to age-matched control rats. No differences were observed in the distance travelled (C) and total arm entries (D) between the two-groups. Data expressed as mean \pm SEM, ${ }^{*} p<0.05$, t-test, $\mathrm{n}=8$ rats.

Figure 4. Impaired recognition memory in POX intoxicated rats on NOR test. (A) POX rats exhibited a negative discrimination ratio indicative of impaired recognition memory that was significantly lower compared to a positive discrimination ratio observed in age matched control rats. (B) No significant differences were observed in the exploration time during the identical object-sample phase test session between the two groups. Data expressed as mean \pm SEM, ${ }^{*} p<0.05$, t-test, $\mathrm{n}=8$ rats. 
Fig. 1

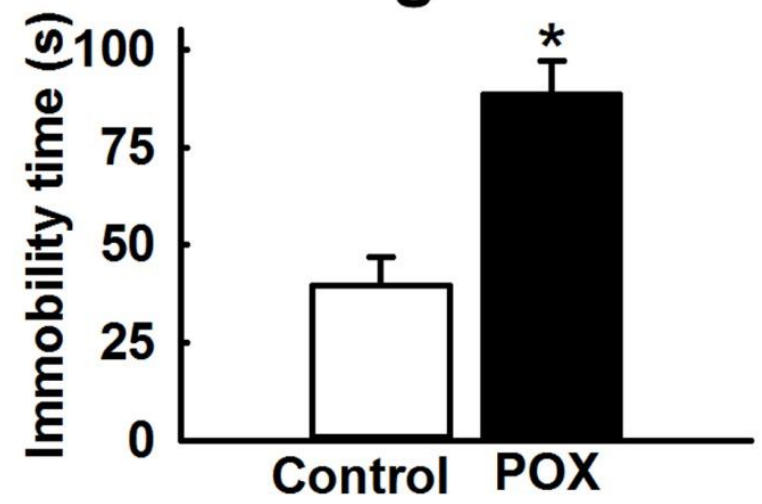


Fig. 2

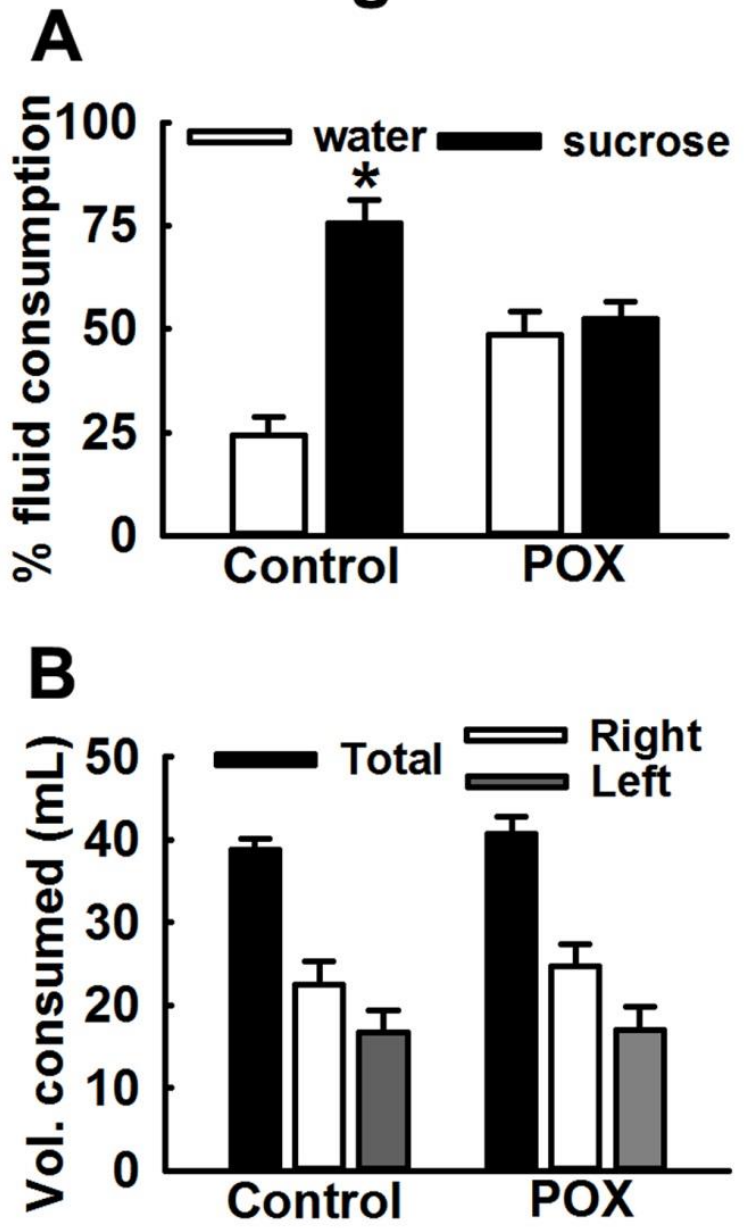


Fig. 3

A

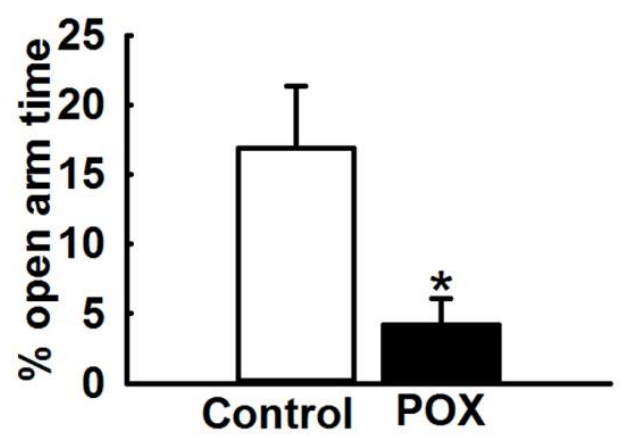

C

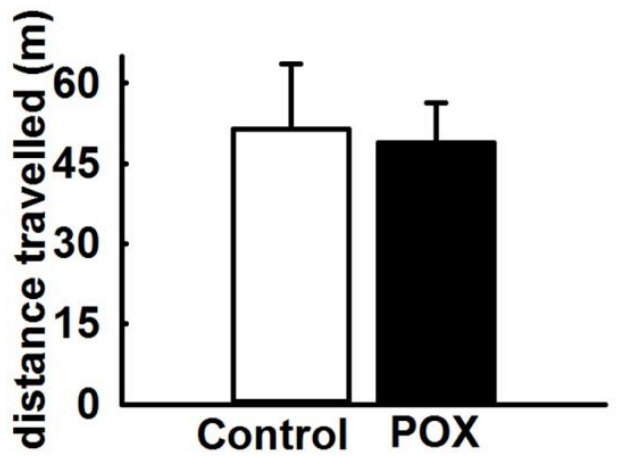

B

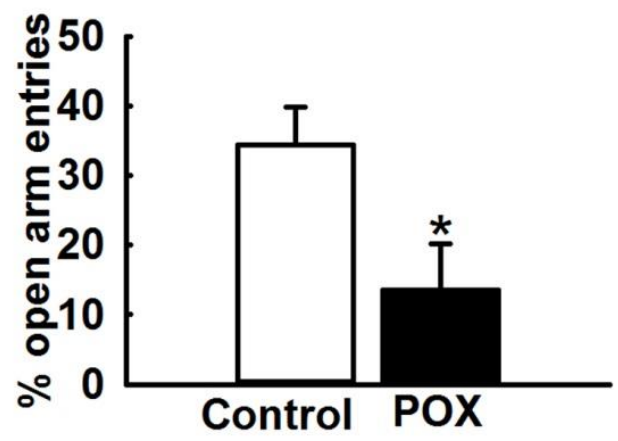

D

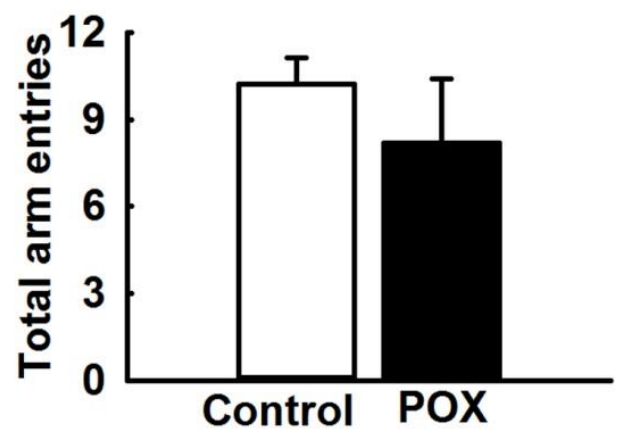




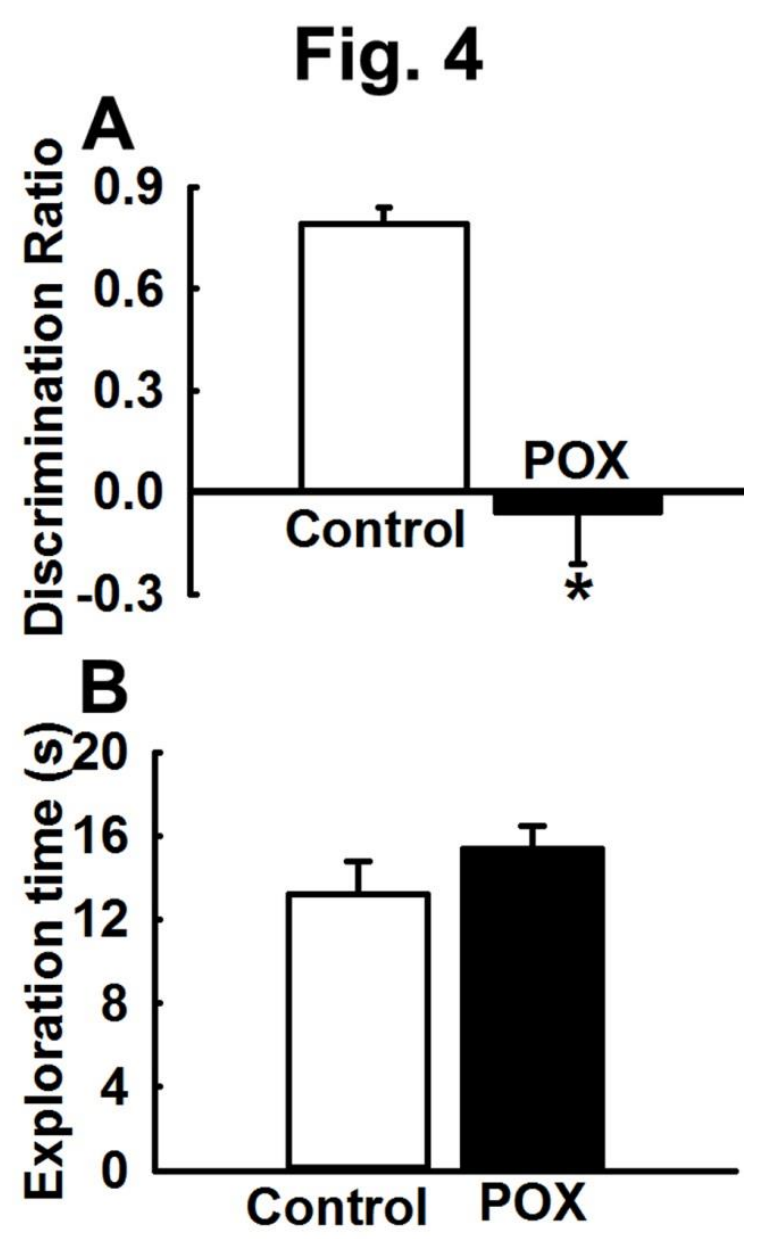

